\title{
Is Body Surface Area the Appropriate Index for Glomerular Filtration Rate?
}

\author{
Liesbeth Hoste and Hans Pottel \\ Katholieke Universiteit Leuven Campus Kortrijk \\ Belgium
}

\section{Introduction}

Indexing glomerular filtration rate (GFR) for body surface area (BSA) is routine practice, but criticism has been raised on indexing GFR for BSA in children, obese and anorectic patients. Over the years other ways of indexing GFR have been proposed, including height, lean body mass, body weight, ideal weight, plasma volume, total body water and especially extracellular volume (ECV). Based on a literature review and on statistical analyses of GFR data of children, we consider the following main questions: Why do we normalize GFR for BSA? Is it really necessary to index GFR? And if so, are there other or better ways to normalize GFR?

\section{History of BSA formulas}

In the late 19th century, Max Rubner introduced the 'surface' hypothesis that the metabolic rate of any animal is closely related to BSA. (Rubner, 1883) Although we know today that this assertion is not correct, the surface hypothesis was well embraced at that time and considered as a law. Since measuring heat production with direct calorimety is rather complex, BSA was seen as an alternative for reflecting the metabolic rate. The question then became how to measure BSA?

\subsection{The formula of Meeh (1879)}

In 1879, Meeh published a formula to estimate BSA from body weight. (Meeh, 1879) Meeh derived his formula in 6 adults and 10 children, using a variety of methods. Some parts of the body were marked out in geometrical patterns, which were then traced on transparent paper. Next, the surface of these areas was determined by geometry, or if the pieces of paper were very irregular, by weighing. Some of the cylindrical parts of the body were wound with strips of millimeter paper like a bandage. The widely used formula proposed by Meeh was based on the fundamental mathematical law which states that similar solids have a surface area proportional to the $2 / 3$ power of their volumes. He used body weight to represent volume, and derived the following equation, based on dimensional analysis: $\mathrm{BSA}=0.1053$ weight $2 / 3$.

\subsection{The formula of DuBois \& DuBois (1916)}

Meeh's formula remained standard until 1916 when the DuBois brothers published several manuscripts exploring different formulas to measure the BSA. To determine the surface area 
of the various parts of the body, the brothers tightly covered patients' bodies with manila paper molds. The area of the mold was determined by cutting it in pieces and placing the pieces flat on photographic film which was exposed to sunlight. The unexposed paper was then cut and weighed. The BSA was derived from the weight divided by the average density of the photographic paper. The brothers used 19 detailed measurements from 7 different body parts of 5 patients to derive a geometric formula to predict BSA that had an acceptably limited error compared with the true BSA. (DuBois \& DuBois, 1915) One year later, DuBois \& DuBois added 4 patients to their 5 initial patients and they derived, by iteration, a 'height-weight' formula from this dataset. Among the 9 patients, there was a child of 2 suffering from rickets, an obese adult female, a 36 year old adult with mental and physical development of an 8 year old and a diabetic patient of 18 with a very low body mass index. (DuBois \& DuBois, 1916)

In order to construct their formula, the brothers concluded that the error in Meeh's formula could be reduced by also taking height into consideration, since adding height made the formula more applicable for patients of the same general shape but differing somewhat in relative dimensions. DuBois \& DuBois assumed that area could be estimated from the formula $\mathrm{BSA}=\mathrm{CW}^{\mathrm{a}} \mathrm{H}^{\mathrm{b}}$, with $\mathrm{C}$ a constant, $\mathrm{W}=$ weight in $\mathrm{kg}$ and $\mathrm{H}=$ height in $\mathrm{cm}$. As the left side in this equation has the dimensions of an area (squared length $\mathrm{L}^{2}$ ), the right side needs to have the same dimensionality. As weight is considered proportional to a volume ( $\left.\mathrm{L}^{3}\right)$ when mass density is considered constant, the following dimensionality condition is obtained: $2=3 a+b$. This constraint reduces the complexity of the problem, as only two parameters (the constant $C$ and $a$ or $b$ ) have to be obtained from the data. Logarithmic transformation of both sides of the equation reduces the problem even further to a simple linear regression fit. With the aid of a computer this is easily performed with modern statistical methodology, but back in 1916, DuBois \& DuBois had to use repetitive combinations for $a$ and $b$ to arrive at their final and today's well known DuBois \& DuBois formula: BSA $=0.007184$ * $\mathrm{W}^{0.425}{ }^{*} \mathrm{H}{ }^{0.725}$.

\subsection{The search for a better formula (1935-2010)}

In the following years, several authors have proposed other formulas using more sophisticated statistical techniques and studying larger populations. In 1935, Boyd listed 401 direct measurements of surface area obtained by direct coating, triangulation or surface integrator methods. (Boyd, 1935) Boyd recommended 2 formulas for calculating surface area, one based on height and weight and one based on weight only. The formula involving height and weight was superior to that based on weight alone. In 1970, Gehan \& George used Boyd's database to refine the exponents in the equation proposed by DuBois \& DuBois. (Gehan \& George, 1970) Although Gehan \& George did find that their equation failed for small children and obese subjects, no further attempt was made to assess other models relating height and weight to BSA. In 1978, Haycock et al. started calculating BSA by using a geometric method with schematic reduction of body segments to cylinders and a sphere. (Haycock et al., 1978) Validation in 81 persons, from premature infants to adults, was done by comparison with the DuBois \& DuBois formula (DuBois \& DuBois, 1916) for adults and with the Faber \& Melcher formula (Faber \& Melcher, 1921) for infants. The formulas of Boyd, Gehan \& George and Haycock rely on linear regression of logarithmically transformed weight and height measurements. The authors published equations of the type of DuBois \& DuBois, in which different values for the constants $\mathrm{a}, \mathrm{b}$ and $\mathrm{C}$ were obtained. Although the constraint $3 a+b=2$ was not used in the construction of these formulas, one may notice that the dimensionality condition is nearly always fulfilled. For Boyd's formula 
$3 a+b$ gives a value of 1.95 , the formula of Gehan \& George gives a value of 1.97 and Haycock's equation gives 2.01. In 1987, Mosteller also used dimension analysis to derive a simplified formula from that of Gehan \& George, which is easier to remember. (Mosteller, 1987) In 2000, Shuter \& Aslani presented the original results of the DuBois \& DuBois formula on a more robust statistical footing (non-linear regression), yielding values for the model constants that would have been obtained if the brothers had had access to modern statistical methods and modern computers. (Shuter \& Aslani, 2000) Since fitting BSA estimates directly by non-linear regression is more accurate, this was the technique Livingston \& Lee preferred in 2001 to derive their formula which, like Meeh's formula, only relies on body weight. Based on the data of 47 patients, they developed an equation, which is especially useful to predict BSA in obese patients. (Livingston \& Lee, 2001)

In general, the correlation between all these formulas is high (Verbraecken et al., 2006), but there are no clear advantages of the others over the DuBois formula, which remains the best known and most used formula today. Although, it is unrealistic to expect that one single height-weight formula predicts BSA with the same accuracy in all people, since humans change shape as they grow and age. Errors in height-weight formulas will be exaggerated in very small people like children or in obese patients. It has been shown that for children weighing below $10 \mathrm{~kg}$ and in the obese population, the DuBois formula does not give the best results. For children with a weight below $10 \mathrm{~kg}$ the formulas of Haycock or Mosteller are preferred (van der Sijs \& Guchelaar, 2002), for obese persons the formula of Livingston \& Lee is advised. (Livingston \& Lee, 2001) A simulation with virtual data showed us that the formulas of Boyd, Gehan \& George, Haycock and Mosteller overestimate the BSA as compared to the BSA calculated with the DuBois \& DuBois formula. In Figure 1 one may observe an elliptical shape of the data in the plot of the BSA calculated with the Gehan \& George equation against the DuBois \& DuBois calculated BSA. The graph also illustrates that a BSA of $1.73 \mathrm{~m}^{2}$ calculated by DuBois \& DuBois can vary between $1.65 \mathrm{~m}^{2}$ and $2.15 \mathrm{~m}^{2}$ if calculated by the Gehan \& George equation. This elliptical shape is also seen when plotting the formulas of Boyd, Gehan \& George, Haycock et al. and Mosteller against the DuBois \& DuBois formula (graphs are not shown).

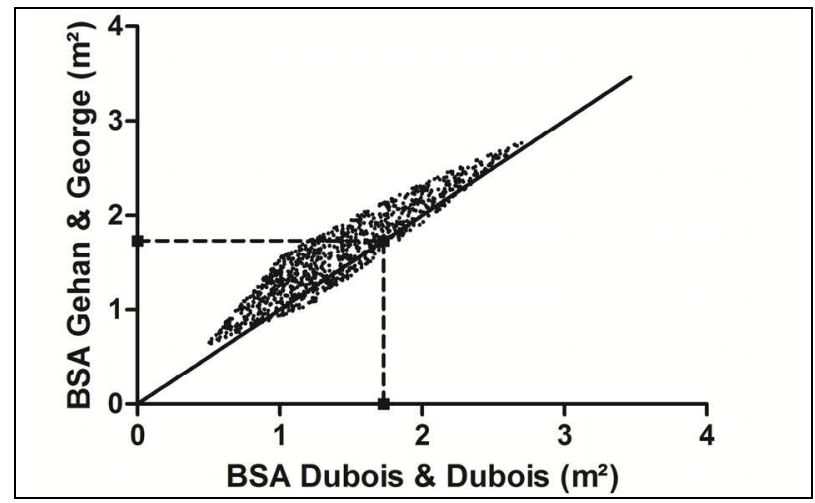

Fig. 1. BSA calculated with the formula of Gehan \& George plotted against the DuBois \& DuBois calculated BSA. The solid line is the identity line. The dotted lines indicate a body surface area of $1.73 \mathrm{~m}^{2}$. 
For the determination of the body surface area of Indians, Banerjee et al. updated the constant C of the formula of DuBois \& DuBois. (Banerjee \& Bhattacharya, 1961; Banerjee \& Sen, 1955) Nwoye et al. computed new variables for height and weight formulas that accurately predict the surface area of Africans and Saudi males. (Nwoye, 1989; Nwoye \& AlShehri, 2003) The formula of Fujimoto et al. was developed to calculate the BSA in the Japanese population (Fujimoto et al., 1968), while Stevenson developed a formula to estimate the BSA in Chinese people. (Stevenson, 1937) Interesting is that recently, a new 3Dscanning method for measuring BSA is introduced and used to propose new BSA formulas. (Tikuisis et al., 2001; Yu et al., 2010) An overview of a non exhaustive list of BSA formulas is given in Table 1.

\begin{tabular}{|c|c|}
\hline AUTHOR & FORMULA \\
\hline Meeh (1879) & BSA $=0.1053$ weight $2 / 3$ \\
\hline DuBois \& DuBois (1916) & BSA $=0.007184 *$ weight $0.425 *$ height 0.725 \\
\hline Faber \& Melcher (1921) & $\mathrm{BSA}=0.007850 *$ weight $0.425 *$ height 0.725 \\
\hline Boyd (1935) & BSA $=0.017827 *$ weight $0.4838 *$ height 0.5 \\
\hline Stevenson (1937) & $\mathrm{BSA}=0.0128 *$ weight $+0.0061 *$ height -0.1529 \\
\hline Banerjee \& Sen (1955) & BSA $=0.007466 *$ weight $0.425 *$ height 0.725 \\
\hline Banerjee \& Bhattacharya (1961) & BSA $=0.0070 *$ weight $0.425 *$ height 0.725 \\
\hline Fujimoto et al. (1968) & $\mathrm{BSA}=0.008883 *$ weight $0.444 *$ height 0.663 \\
\hline Gehan \& George (1970) & BSA $=0.0235 *$ weight 0.51456 * height 0.42246 \\
\hline Haycock et al. (1978) & BSA $=0.02465 *$ weight $0.5378 *$ height 0.3964 \\
\hline Mosteller (1987) & $\mathrm{BSA}=($ weight $0.5 *$ height 0.5$) / 60$ \\
\hline Nwoye (1989) & BSA $=0.001315 *$ weight $0.2620 *$ height 1.2139 \\
\hline Shuter \& Aslani (2000) & BSA $=0.00949 *$ weight $0.441 *$ height 0.655 \\
\hline Livingston \& Lee (2001) & $\mathrm{BSA}=0.1173 *$ weight 0.6466 \\
\hline Tikuisis for men (2001) & BSA $=0.01281^{*}$ weight $0.44 *$ height 0.60 \\
\hline Tikuisis for women (2001) & BSA $=0.01474$ * weight 0.47 * height 0.55 \\
\hline Nwoye \& Al-Sheri (2003) & BSA $=0.02036$ * weight $0.427 *$ height 0.516 \\
\hline Yu et al. (2010) & BSA $=0.00713989 *$ weight $0.4040 *$ height 0.7437 \\
\hline
\end{tabular}

Table 1. Overview of BSA formulas. BSA is expressed in $\mathrm{m}^{2}$, weight in $\mathrm{kg}$, height in $\mathrm{cm}$.

\section{Indexing GFR for BSA}

The GFR of a healthy person can vary from $1 \mathrm{ml} / \mathrm{min}$ for neonates to $200 \mathrm{ml} / \mathrm{min}$ for large adults. White et al. stated that this makes the interpretation of a GFR measurement not easy for the physician unless the physician is familiar with the expected normal value for the particular patient. (White \& Strydom, 1991) Therefore, it would be worth considering to normalize GFR in such a way that the influence of patient variables is minimal.

In 1928, renal function was for the first time corrected for BSA by McIntosh et al. (McIntosh et al., 1928) McIntosh et al. built their indexation theory on the experience of the research of Taylor et al., which assumed a correlation between urea excretion and the weight of the kidneys in rabbits. Taylor et al. also showed that there exists a better correlation between kidney weight and BSA, than between kidney weight and animal's weight. (Taylor et al., 1923) When McIntosh et al. on their turn corrected urea clearances of 18 adults and 8 children for BSA, the data from the small children yielded the same normal values as for adults. In the footsteps of Taylor et al., MacKay illustrated a direct correlation between BSA 
and kidney weight and between BSA and urea excretion in humans. (MacKay, 1932). Based on these observations, the indexation of GFR for BSA became standard in the medical community.

McIntosh et al. also introduced the use of the reference surface area of $1.73 \mathrm{~m}^{2}$, which was the average calculated BSA of 25 year old Americans at that time. The value of $1.73 \mathrm{~m}^{2}$ has served the physiological community well for nearly 80 years, but is clearly no longer applicable to modern Western populations, as has been shown by Heaf et al. (Heaf, 2007) A value of $1.95 \mathrm{~m}^{2}$ would probably be more appropriate for the average BSA of today's 25 year old adults in America. Switching from $1.73 \mathrm{~m}^{2}$ to $1.95 \mathrm{~m}^{2}$ has severe repercussions for the current classification system for Chronic Kidney Disease, which is based on fixed limits of $15,30,60$ and $90 \mathrm{ml} / \mathrm{min} / 1.73 \mathrm{~m}^{2}$. The importance of $1.73 \mathrm{~m}^{2}$ or $1.95 \mathrm{~m}^{2}$ is not the value as such, but the fact that it serves as a reference point. Therefore, there is no need to change the reference value.

Recently, Delanaye et al. recalculated Taylor's correlation and noted that the correlation between BSA and kidney weight was not different from that between kidney weight and body weight. (Delanaye et al., 2009a) This indicates that the BSA-indexation theory of McIntosh et al. was based on false assumptions.

\section{Is it necessary to index GFR?}

In 1928, McIntosh et al. already noticed that indexing is not necessary for 'normally built' people. McIntosh stated: "The nature of the standard clearance formula is such that correction for body size in persons between 62 and 71 inches in height does not exceed 5 per cent, and in tests of renal function may be neglected." (McIntosh et al., 1928) It follows that in longitudinal studies, the absolute GFR should be used for evaluating the kidney function, avoiding the use of BSA-indexed GFR which is affected by weight changes. On the other hand, indexation seems to be necessary to compare different patient values and to allow comparison with fixed reference values. Three cases will here be studied to illustrate these statements: (1) the GFR of a small and heavy person will be compared with each other, (2) the GFR evolution during childhood will be presented and (3) the GFR of two adult men, one with a stable weight and one with a weight that increases with age, will be followed.

\subsection{Case 1: Comparison of the GFR of a small and heavy person}

Imagine the body of a small and heavy person as a small and big pond with the kidneys as a pump and filter combination to clear the dirt out of the pond. The dirt is equally present in the pond and the pump sends a constant flow through the filter which is here assumed to have the same clearing efficiency, after which the cleared water is drained off in the pond again. Repeated cycles will diminish the concentration of dirt in the water. If the small and the big pond both have an equally working pump and filter combination of $60 \mathrm{ml} / \mathrm{min}$, it will take much longer for the big pond to be cleared than it will take for the small pond. Or the pump of the big pond will have to work at a higher rate than the pump of the small one to clear all the dirt out of the water in the same time. This indicates that the function of the pumps must be corrected for a value that describes the size of the ponds in a certain way.

If we normalize the absolute GFR of $60 \mathrm{ml} / \mathrm{min}$ of the small and heavy person for the BSA (Table 2), then we get a corrected cGFR of $73 \mathrm{ml} / \mathrm{min} / 1.73 \mathrm{~m}^{2}$ for the small person as opposed to a much smaller cGFR of $46 \mathrm{ml} / \mathrm{min} / 1.73 \mathrm{~m}^{2}$ for the heavy person. Once the GFR is BSA corrected, it becomes clear that the small person has a better kidney function than the 
heavy person. We may conclude that indexation of the GFR is necessary to allow comparison between different patients.

\begin{tabular}{|l|c|c|}
\hline DATA & SMALL PERSON & HEAVY PERSON \\
\hline Age (years) & 55 & 55 \\
Length (cm) & 150 & 190 \\
Weight (kg) & 50 & 100 \\
BSA (m) & ) & 2.28 \\
GFR (ml/min) & 1.43 & 60 \\
cGFR (ml/min/1.73m ${ }^{2}$ ) & 60 & 46 \\
\hline
\end{tabular}

Table 2. Data for comparison of the GFR of a small and heavy person.

\subsection{Case 2: GFR evolution during childhood}

In this case, we study the evolution of a healthy boy during his childhood. In Table 3 the age, length, weight, BSA, absolute GFR and cGFR of the boy at the age of 3.5, 7.5, 11 and 15 years are listed. For the average healthy boy, the corrected cGFR remains constant during childhood (from 2-3 years till 14 years) (Piepsz et al., 2008, 2009) but the absolute GFR values of the boy at different ages cannot be compared with each other. From the data in Table 3 or by inspection of Figure 2, one may observe an increasing absolute GFR, as well as an increasing BSA as a function of age because the child and his kidneys are still growing. Referring to our pond analogy, one could say that the pump and filter combination of the pond are constantly changing in order to keep the pond clearance at the same rate. Correcting GFR for BSA leads to the same clearance value, independent of age. With the corrected cGFR, the child's kidney function can be followed, regardless of his growth process.

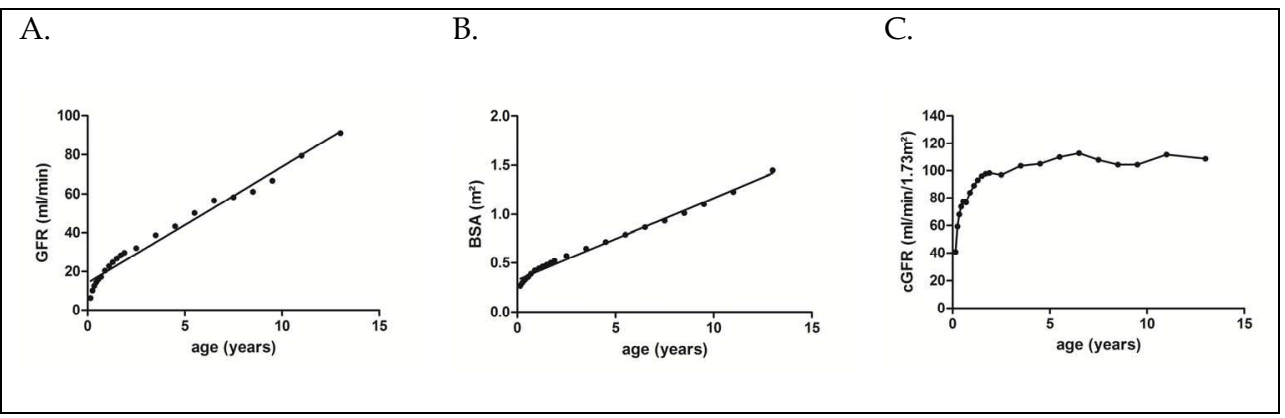

Fig. 2. (A) Absolute GFR as a function of age; (B) BSA as a function of age; (C) cGFR as a function of age.

\subsection{Case 3: GFR evolution during adulthood}

It is known that the GFR shows an age-dependent decline for the average healthy person, which may be considered as part of the normal biological process of senescence. The body weight is also often increasing with age. That is why in this case we study the GFR of two adult men, one with a stable weight during adulthood and one with a weight that increases with age (Table 4 ). The man with a stable weight has a normal age-dependent decreasing 


\begin{tabular}{|c|c|c|c|c|}
\hline DATA & \multicolumn{4}{|c|}{ HEALTHY BOY } \\
\hline Age (years) & 3.5 & 7.5 & 11 & 15 \\
\hline Length (cm) & 99 & 126.5 & 146 & 173 \\
\hline Weight (kg) & 15.5 & 25 & 37 & 58.5 \\
\hline BSA $\left(\mathrm{m}^{2}\right)$ & 0.64 & 0.94 & 1.24 & 1.70 \\
\hline GFR (ml/min) & 44.5 & 65.0 & 86.0 & 118.0 \\
\hline cGFR (ml/min/1.73m²) & 120 & 120 & 120 & 120 \\
\hline
\end{tabular}

Table 3. Data for GFR evolution during childhood.

GFR. The man with the increasing weight has a GFR which is decreasing with age, but the cGFR is faster decreasing because of his increasing body surface area. There is indeed a double decreasing effect on the corrected cGFR. In Table 4, it is shown that the man with a stable weight has a cGFR of $111 \mathrm{ml} / \mathrm{min} / 1.73 \mathrm{~m}^{2}$ at the age of 65 . However, the man with the increased weight has a cGFR of $95 \mathrm{ml} / \mathrm{min} / 1.73 \mathrm{~m}^{2}$ at the age of 65 years. This illustrates that weight-changes influence the BSA corrected GFR. Therefore one may wonder whether BSA is the appropriate index for GFR.

\begin{tabular}{|c|c|c|c|c|c|c|c|c|}
\hline DATA & \multicolumn{4}{|c|}{ MAN - STABLE WEIGHT } & \multicolumn{4}{|c|}{ MAN - INCREASING WEIGHT } \\
\hline Age (years) & 18 & 35 & 50 & 65 & 18 & 35 & 50 & 65 \\
\hline Length (cm) & 180 & 180 & 180 & 180 & 180 & 180 & 180 & 180 \\
\hline Weight (kg) & 70 & 70 & 70 & 70 & 70 & 80 & 90 & 100 \\
\hline BSA $\left(\mathrm{m}^{2}\right)$ & 1.89 & 1.89 & 1.89 & 1.89 & 1.89 & 2.00 & 2.10 & 2.20 \\
\hline GFR (ml/min) & 142 & 138 & 133 & 121 & 142 & 138 & 133 & 121 \\
\hline cGFR $\left(\mathrm{ml} / \mathrm{min} / 1.73 \mathrm{~m}^{2}\right)$ & 130 & 126 & 122 & 111 & 130 & 119 & 110 & 95 \\
\hline
\end{tabular}

Table 4. Data of an adult man.

\subsection{Conclusion}

The cases described above illustrate that indexation is necessary to compare patient values with each other and with reference values. But the question remains whether BSA is the appropriate index for GFR. This has been a subject of debate during the last ten years.

\section{Criticism on indexing GFR for BSA}

Indexing GFR for BSA goes back to 1928 and it has become so conventional that BSAindexing can be considered as an icon in nephrology. Nevertheless, during the last ten years there is increasing criticism on BSA indexation. According to Tanner, the dispersion of differences between data of children and adults is not a very strong argument for BSA indexing. (Tanner, 1949) Neither is the argument that BSA indexation is necessary because everybody does it and in that way results become comparable. (Kronmal, 1993) BSA indexation is also seriously questioned in populations with unusual anthropometric data such as in children, in obese or lean persons. According to Bird et al. indexing GFR for BSA does not suit children because they naturally have a relatively high BSA simply because of their small size. (Bird et al., 2003) Delanaye et al. studied obese and anorectic patients. (Delanaye et al., 2005, 2009a, 2009b) In those patients, the consequences of indexing for BSA are much more important since the cGFR is influenced by weight-variation and may obscure variations in the absolute GFR. That is why Delanaye et al. recommend using the absolute 
GFR values instead of the cGFR, especially in 'abnormal' body size populations. (Delanaye, 2009a, 2009b) Geddes et al. started their article with another interesting case, in which they show that indexing for BSA can lead to a different clinical decision especially in the overweight. (Geddes et al., 2008) The case described by Geddes et al. concerns a 54 year old obese man who wants to donate a kidney to his own son. Published International guidelines and UK guidelines recommend a minimum GFR of $80 \mathrm{ml} / \mathrm{min} / 1.73 \mathrm{~m}^{2}$ and 75 $\mathrm{ml} / \mathrm{min} / 1.73 \mathrm{~m}^{2}$ respectively for a 55 year old kidney donor. Direct measurement of the kidney function of the man resulted in an absolute GFR of $87 \mathrm{ml} / \mathrm{min}$ and in a corrected cGFR of $77.9 \mathrm{ml} / \mathrm{min} / 1.73 \mathrm{~m}^{2}$. It is clear that the difference between the absolute GFR and the cGFR is of major importance in this case. Above all, we may not forget that there are several formulas to estimate the BSA. In Table 5 we illustrate that using another BSA formula can influence the decision. Since the studied man is obese (BMI of 31.5), the formula of Livingston \& Lee (Livingston \& Lee, 2001), which results in a negative decision towards the kidney donation, should probably be preferred.

\begin{tabular}{|l|c|c|}
\hline FORMULA & BSA ( $^{\mathbf{2}}$ ) & cGFR (ml/min/1.73m \\
)
\end{tabular}

Table 5. BSA calculated with frequently used BSA formulas and comparative BSA indexed GFR values of a 54 year old man with a length of $165 \mathrm{~cm}$, a weight of $86 \mathrm{~kg}$ and an absolute GFR of $87 \mathrm{ml} / \mathrm{min}$.

\section{Are there alternatives to index GFR?}

One may wonder why indexing GFR for BSA is still routinely used, despite all the criticism. The fact that the frequently used estimated eGFR formulas as well as the fixed cut-off values of the current Chonic Kidney Disesase classification system are both expressed in $\mathrm{ml} / \mathrm{min} / 1.73 \mathrm{~m}^{2}$ might be a first and important reason why it is not obvious to stop indexing GFR for BSA. A second reason might be that indexing GFR for BSA has almost no consequences for normally built people. Questions about the effectiveness of indexing GFR for BSA only appear when 'abnormal' body size populations like children or obese patients are studied. Due to the limitations of correcting GFR for BSA in those specific populations a whole array of alternative variables for indexing GFR has been suggested.

The most evoked factor to index GFR in obese patients is height. Two studies have shown that correcting GFR for height is identical in obese and non-obese populations, whereas corrected GFR for BSA is inadequately lower in the obese population. (Anastasio et al., 2000; Schmieder et al., 1995) Delanaye et al. stated that since the range of height in the population is narrower than the range of weight (giants and dwarfs are less numerous than obese or anorectic) it is logical that indexing for height will decrease the dispersion of data in the adult population. (Delanaye, 2009a) Other height-dependent indexators that have been proposed to normalize the GFR are lean body mass (Hallynck et al., 1981; Kurtin, 1988), ideal weight (Walser, 1990) and even squared height. (Mitch \& Walser, 2000) Also body weight has been indicated as a 
possible indexator. (Peters et al., 1994b) However, it intuitively seems better to correct GFR for body fluid, since one of the roles of the kidneys is to regulate body fluid composition. Different GFR-indexators in that area are total body water (Bird, 2003; McCance \& Widdowson, 1952), plasma volume (Peters et al., 1994a) or extracellular volume (ECV) (Bird, 2003; Peters, 1992, 1994b, 2000; White \& Strydom, 1991) In 1952, McCance et al claimed that total body water was the best variable to index the GFR for children. (McCance \& Widdowson, 1952) But since total body water is complex to determine every time the GFR is measured, ECV became the most considered alternative to index the GFR, especially in children.

\subsection{Comparison of indexing GFR for BSA, height and ECV}

In this section we compare indexing GFR for BSA and for the alternatives height and ECV. True mathematical evidence for normalizing a physical quantity by any index is wellknown. (Turner \& Reilly, 1995) The uncorrected quantity should be a linear function of the indexator with zero intercept (Figure 3A). After indexation the relationship between the indexed quantity and the indexator then completely disappears (Figure 3B).

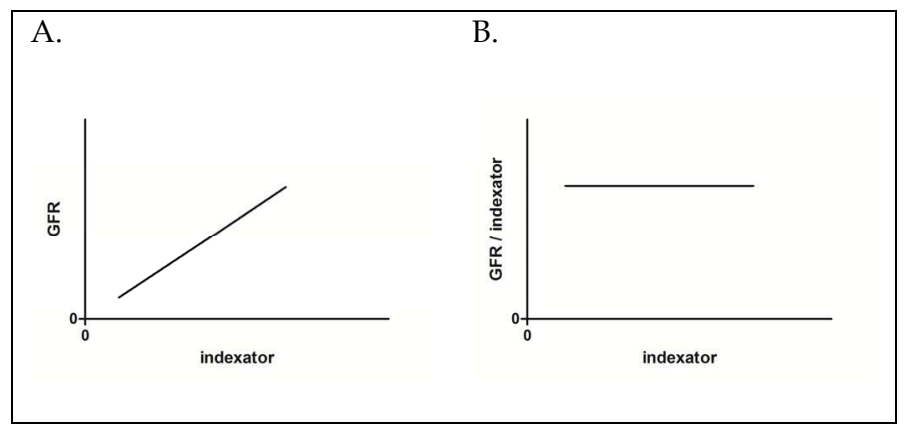

Fig. 3. (A) Linear regression of GFR versus the indexator; (B) Disappearance of the relationship indexed GFR-indexator.

Because of their rapidly increasing size and renal maturation, children may give insight into the properties of different normalization indexes. Publicly available data are used to test the mathematical requirements for the indexators BSA, height and ECV. The dataset contains data for healthy children (between 0 and 15 years) of absolute and BSA-corrected median GFR values (51Cr-EDTA), median heights and weights. (Pottel et al., 2010) ECV of the children was calculated with the ECV formula of Bird et al. (Bird, 2003)

\subsubsection{Indexing GFR for BSA}

When considering median absolute GFR values versus BSA, one may observe a linear relationship ( $\mathrm{y}=59.96 \mathrm{x}$ with $\mathrm{R}^{2}=0.96$ ) (Figure 4A). When GFR is indexed for BSA, the relation GFR-BSA disappears once the kidneys reach maturity (Figure 4B). So, the mathematical requirement for an indexator is fulfilled.

\subsubsection{Indexing GFR for height}

The most evoked factor to index GFR in obese patients is height. (Anastasio, 2000; Schmieder, 1995) Again, we studied the fundamental prerequisite relationship GFR-height and the lack of relationship between GFR indexed for height and height. When the 


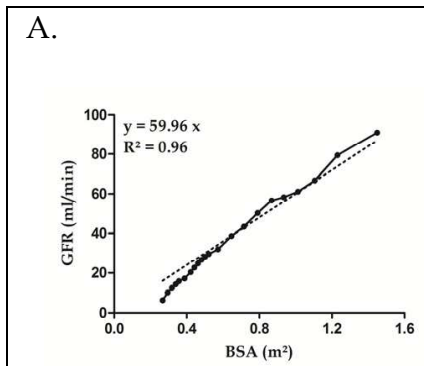

B.

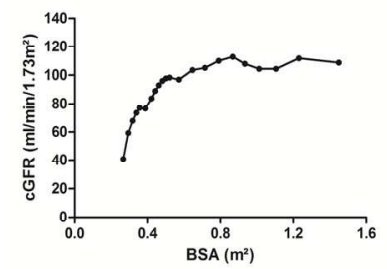

Fig. 4. (A) Linear relationship between absolute GFR and BSA; (B) Disappearance of the relationship between GFR and BSA, when GFR is corrected for BSA.

absolute median GFR values of children were plotted versus height, the results were disappointing $\left(y=42.01 x\right.$ with $\left.\mathrm{R}^{2}=0.77\right)$ (Figure $\left.5 \mathrm{~A}\right)$. But when the absolute median GFR values of the children are plotted against the squared height, the regression is better $\left(y=36.89 x\right.$ with $\left.R^{2}=0.99\right)$ (Figure $\left.5 C\right)$ than the regression of GFR against BSA (Figure 4A).

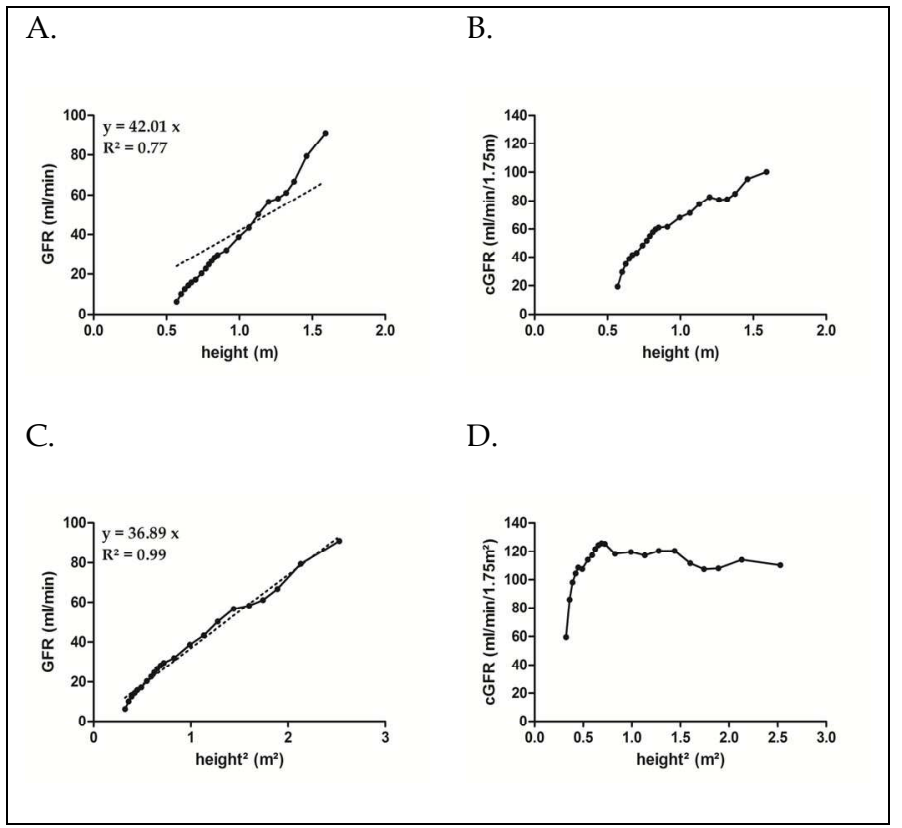

Fig. 5. (A) Linear relationship between absolute GFR and height; (B) No disappearance of the relationship between GFR and height, when GFR is indexed for height; (C) Linear relationship between absolute GFR and squared height; (D) Disappearance of the relationship between GFR and squared height, when GFR is corrected for squared height.

Although height is the most often considered index in the obese population, further research whether height or squared height may serve as a correction factor for GFR is necessary. 
Delanaye et al. studied the fundamental mathematical requirement between GFR and height in a limited obese population, but did not find a satisfying linear relationship. (Delanaye, 2005) A better relationship may be found when squared height is used instead of height. It is known that correcting GFR for BSA may cause problems when considering obese or anorectic people. Indexing for height may lead to the same errors, especially in populations with extreme height.

\subsubsection{Indexing GFR for ECV}

The earliest study of ECV normalisation is by Newman et al., who argued that since the function of the kidneys is to sustain the chemical composition of the extracellular fluid, ECV is more closely related to kidney function than BSA. (Newman et al., 1944) Also the research group of Peters et al. intensively contemplated a change to using ECV to index the GFR. (Bird, 2003; Peters, 1992, 1994b, 2000) Furthermore, several scientists showed a high correlation between BSA and ECV. (Abraham et al., 2011; Newman, 1944; Peters, 2004; White \& Strydom, 1991) One could therefore argue that since this equivalence exists, either ECV or BSA can be used to index the GFR. Various studies suggested that ECV is at least a more appropriate index for GFR in children. (Bird, 2003; Friis-Hansen, 1961; Peters, 1994b, 2000) According to Peters et al. this arises from the fact that children have a higher body surface area than adults in relation to their weight, which leads to an overcorrection of the GFR when BSA is used as an indexator. It has also been shown that humans change shape as they grow, which undermines the validity of BSA as an indexation variable. (Peters, 2004) Another argument to prefer ECV above BSA is the fact that ECV is three-dimensional wheras BSA is two-dimensional. (Peters, 2000)

Mathematical evidence for normalizing GFR for ECV based on our children's database can be found in Figure 6.

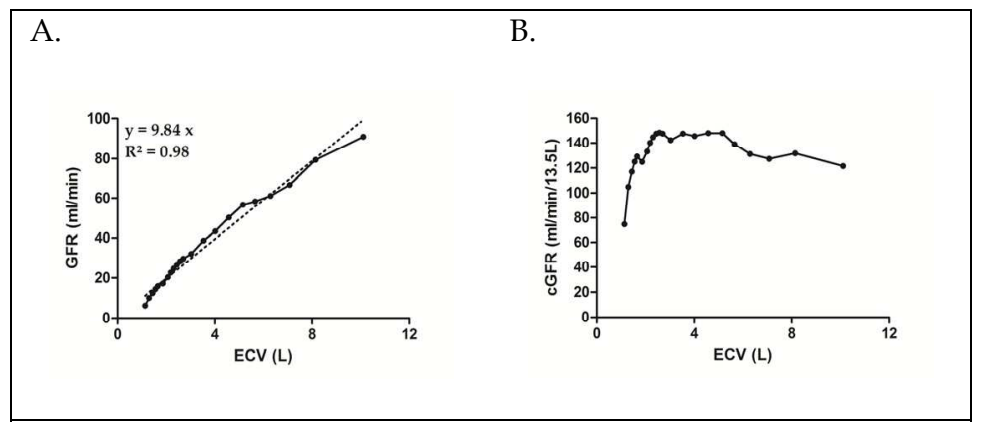

Fig. 6. (A) Linear relationship between absolute GFR and ECV; (B) Disappearance of the relationship between GFR and ECV, when GFR is corrected for ECV.

In 1961, Friis-Hansen developed a formula to estimate ECV in children. The formula is, like the DuBois \& DuBois formula, of the form constant * weighta ${ }^{*}$ height ${ }^{\mathrm{b}}$. (Friis-Hansen, 1961) In 2003, a similar height-weight ECV equation was published by Bird et al. (Bird, 2003) In 2011, Abraham et al. found that height provided most of the information in the estimation of ECV and that ECV could be simply estimated from ECV $=$ height * $\sqrt{w}_{\text {weight. }}$ (Abraham, 2011) 


\begin{tabular}{|l|l|}
\hline \multicolumn{1}{|c|}{ AUTHOR } & \multicolumn{1}{c|}{ FORMULA } \\
\hline Friis-Hansen $(1961)$ & $\mathrm{ECV}=0.0682 *$ weight $0.400 *$ height 0.633 \\
Bird et al. (2003) & $\mathrm{ECV}=0.0215$ * weight 0.647 * height 0.742 \\
Abraham et al. (2011) & $\mathrm{ECV}=$ height * ฟweight $^{\text {weight }}$ \\
\hline
\end{tabular}

Table 6. Height and weight based formulas to estimate ECV. ECV is expressed in L, weight in $\mathrm{kg}$ and height in $\mathrm{cm}$, except in the formula of Abraham et al. where height is in meter.

When considering changing GFR indexing from BSA to ECV, the reference ECV value of an average man of $1.73 \mathrm{~m}^{2}$ yields $13.5 \mathrm{~L}$. The ECV corrected GFR would then be expressed in $\mathrm{ml} / \mathrm{min} / 13.5 \mathrm{~L}$. However, one may not forget that ECV is mainly studied as an alternative index in the pediatric population. Little proof exists for application of ECV to adult or obese populations. Nevertheless, the data show that ECV might be a promising index, fulfilling both mathematical requirements. However, one may question the calculation of ECV from a height-weight equation, especially in the obese, based on the same arguments that are used to question the BSA correction.

\subsection{Conclusion}

When correcting for BSA, problems arise for obese or anorectic people. The data show that square height or ECV might be good alternatives to index the GFR (Figure 7). It seems more logical to index GFR with a measure of fluid volume since the purpose of GFR is to regulate body fluid composition. ECV might be a promising index, fulfilling the theoretical requirements, even in the obese.

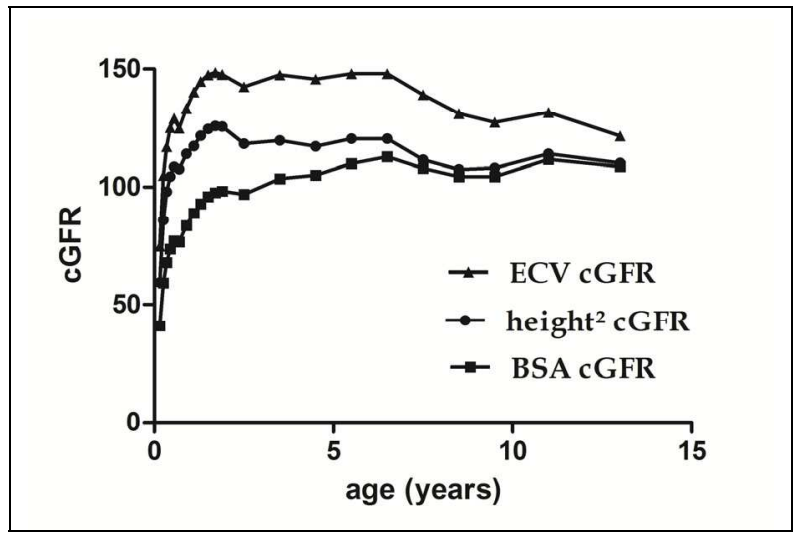

Fig. 7. Comparison of GFR indexed for BSA, squared height and ECV.

\section{Using the slow rate constant or mean transit time as indicator for kidney function}

In 1980, Brochner-Mortenson already pointed out that it would be more rational to express GFR in relation to ECV than in relation to BSA. (Brochner-Mortensen, 1980) He showed that the ratio GFR/ECV could easily be determined when GFR is measured as the plasma clearance of a filtration marker. This is also clearly explained in a review written by Peters. (Peters, 2004) 
The glomerular filtration rate of a person can be determined accurately by measuring the plasma clearance of a filtration marker such as iohexol or ${ }^{51 C r-E D T A}$, which is generaly given by a single bolus injection. The clearance of the marker is followed from plasma sampling at multiple time points over several hours. In case the mixing is immediate, the concentration-time curve may be described as a mono-exponential decay: $c(t)=A e^{-\alpha t}$. The distribution volume in this case is the plasma volume (PV) and the GFR equals the dose of the exogenous marker divided by the area under the concentration-time curve: $\mathrm{GFR}=$ Dose $/(\mathrm{A} / \mathrm{a})$. The concentration at time zero $\mathrm{c}(0)=\mathrm{A}$ equals the dose divided by the distribution volume, and therefore GFR $=a *$ PV or GFR indexed by plasma volume $(\mathrm{GFR} / \mathrm{PV})$ equals the rate constant $\alpha$. As $\alpha$ is expressed in $\min ^{-1}$, the inverse $\mathrm{T}=1 / \mathrm{a}$ expressed in minutes, is the mean transit time. T can be seen as the time needed to reduce the concentration of the filtration marker to $37 \%$ of its original value.

In case the mixing is not immediate (as is the case for iohexol and ${ }^{51} \mathrm{Cr}$-EDTA) and not limited to the plasma volume, the concentration-time curve should be described by a biexponentional decay. The concentration $c$ of the tracer at the time $t$ can then be written as $c(t)=A e^{-a t}+B e^{-\beta t}$. The fast first exponential decay represents mixing of the tracer in the distribution volume of the body as well as filtration of the tracer by the kidneys. After the mixing is completed, the slow second exponential decay indicates that only the kidneys are responsible for the further decrease of the tracer in the plasma. The GFR is defined as the injected dose of the marker divided by the area under the plasma clearance curve. Since the area under the $c(t)$ curve is now equal to $A / \alpha+B / \beta$, the GFR can also be written as the injected dose divided by $A / \alpha+B / \beta$. At time zero, the dose is equal to $(A+B) * P V$, where $\mathrm{PV}$ is the plasma volume, so GFR $=(\mathrm{A}+\mathrm{B}) * \mathrm{PV} /(\mathrm{A} / \alpha+\mathrm{B} / \beta)$. The mean transit time $\mathrm{T}=\left(\mathrm{A} / \mathrm{a}^{2}+\mathrm{B} / \beta^{2}\right) /(\mathrm{A} / \mathrm{\alpha}+\mathrm{B} / \beta)$, expressed in minutes, equals $\mathrm{ECV} / \mathrm{GFR}$, which reduces to $\mathrm{PV} / \mathrm{GFR}$ in case of a mono-exponential decay $(\mathrm{B}=0)$. In that case, $\mathrm{ECV}=\mathrm{PV}$ mathematically. The mean transit time $\mathrm{T}$ or its inverse $1 / \mathrm{T}$ may be seen as an excellent indicator for kidney function, which is in fact the GFR indexed for ECV.

To determine T, a complex procedure with multiple blood samplings (up to 9 samples) is required to obtain the parameters $A, a, B$ and $\beta$ of the bi-exponential decay. Since it is known that the slow component has a larger contribution to the GFR, the rate constant $\beta$ is by itself a close reflection of GFR/ECV $=1 / \mathrm{T}$. Therefore, methods to reduce the blood sampling to only the slow exponential decay ( 2 or 3 samples) were proposed. This onecompartment clearance, also called the slope-intercept technique, always slightly overestimates GFR/ECV since the area under the one-compartment slope is lower than the area under the bi-exponential curve.

In 1972, Brochner-Mortensen published an equation to correct for this overestimation when a ${ }^{51} \mathrm{Cr}$-EDTA clearance is performed in adults (GFR $=0.990778$ * slowGFR -0.001218 * slow $\mathrm{GFR}^{2}$ ). (Brochner-Mortensen, 1972) Two years later, Brochner-Mortensen et al. performed the same study in children which resulted in the correction equation GFR $=1.01$ * slowGFR - 0.0017 * slowGFR. (Brochner-Mortensen et al., 1974) In 1992, Peters proposed the regression equation $\mathrm{GFR} / \mathrm{ECV}=-0.093+1.06 \beta+0.009 \beta^{2}$, relating $\beta$ or the 'approximate' GFR/ECV to the 'true' GFR/ECV based on the bi-exponentional plasma clearance curve of the radio-active agent ${ }^{99} \mathrm{Tc}-\mathrm{DTPA}$. (Peters, 1992) Over the years, improved equations for correcting the slope-intercept measurements in different clinical populations have been published. (Brochner-Mortensen \& Jodal, 2009; Fleming, 2007; Fleming et al., 2004; Jodal \& Brochner-Mortensen, 2009) Although the radio-active agent ${ }^{51} \mathrm{Cr}-\mathrm{EDTA}$ is an excellent filtration marker, it is not accepted in the USA. Lately, the constrast medium iohexol is seen 
as an excellent alternative for the radio-active markers. In 2010, Schwartz et al. showed how the GFR in children could be determined from the slow component of an iohexol clearance curve according to the equation GFR $=1.0019$ * slowGFR -0.001258 * slowGFR 2 . (Schwartz et al., 2010) Since the literature often cautions that the equations are only valid in the populations similar to those in which they were developed, Derek et al. recently tried to develop, based on an iohexol study, an universal formula for use in adults as well as in children. (Derek et al., 2011) The equation of Derek et al. is already expressed in $\mathrm{ml} / \mathrm{min} / 1.73 \mathrm{~m}^{2}$ and is of the form: GFR = slowGFR $/[1+0.12$ (slowGFR/100)].

The rate constant $\beta$, or even $\mathrm{T}$, may be a perfect indicator for kidney function, which immediately allows comparison of the kidney function of different persons with each other. Simulations showed us that the cut-off value of $60 \mathrm{ml} / \mathrm{min} / 1.73 \mathrm{~m}^{2}$ agreed with a $\beta$ value of $0.004 \mathrm{~min}^{-1}$ or a transit time of 4 hours, a cut-off value of $30 \mathrm{ml} / \mathrm{min} / 1.73 \mathrm{~m}^{2}$ agreed with a $\beta$ value of $0.002 \mathrm{~min}^{-1}$ or a transit time of 8 hours.

\section{Conclusions and perspective}

GFR indexing for BSA has little influence on normal body sized people but can be misleading in people with unusual anthropometric data. GFR indexation is necessary to compare the GFR of patients with each other and with reference values. We showed that correcting for squared height or ECV are two good alternatives to normalize the GFR in children. It seems intuitively better to correct GFR for ECV than for BSA because the role of the kidneys is to regulate body fluid composition. Additional research concerning this topic is of particular interest. Also, the rate constant $\beta$ or the mean transit time $\mathrm{T}$ is worth considering as an indicator for kidney function. It must be emphasized that it is important to examine whether other kidney function indicators lead to different clinical decisions.

\section{References}

Abraham, A.G.; Munoz, A.; Furth, S.L.; Warady, B. \& Schwartz, G.J. (2011). Extracellular volume and glomerular filtration rate in children with chronic kidney disease. Clinical Journal of the American Society of Nephrology, Vol.6, No.4, (April 2011) pp.741747, ISSN 1555-9041

Anastasio, P.; Spitali, L.; Frangiosa, A.; Molino, D.; Stellato, D.; Cirillo, E.; Pollastro, R.M.; Capodicasa, L.; Sepe, J.; Federico, P. \& Gaspare De Santo, N. (2000). Glomerular filtration rate in severely overweight normotensive humans. American Journal of Kidney Diseases, Vol.35, No.6, (June 2000) pp.1144-1148, ISSN 0272-6386

Banerjee, S. \& Bhattacharya, A.K. (1961). Determination of Body Surface Area in Indian Hindu Children. Journal of Applied Physiology, Vol.16, No.5, (November 1961) pp.969, ISSN 8750-7587

Banerjee, S. \& Sen, R. (1955). Determination of the surface area of the body of Indians. Journal of Applied Physiology, Vol.7, No.6, (May 1955) pp.585-588, ISSN 0021-8987

Bird, N.J.; Henderson, B.L.; Lui, D.; Ballinger, J.R. \& Peters, A.M. (2003). Indexing glomerular filtration rate to suit children. Journal of Nuclear Medicine, Vol.44, No.7, (July 2003) pp.1037-1043, ISSN 0161-5505

Boyd, E. (1935). The Growth of the Surface of the Human Body. University of Minnesota Press, Minneapolis 
Brochner-Mortensen, J. (1972). A simple method for the determination of glomerular filtration rate. Scandinavian Journal of Clinical \& Laboratory Investigation, Vol.30, No.3, (November 1972) pp.271-274, ISSN 0036-5513

Brochner-Mortensen, J. (1980). A simple single injection method for determination of the extracellular fluid volume. Scandinavian Journal of Clinical \& Laboratory Investigation, Vol.40, No.6, (October 1980) pp.567-573, ISSN 0036-5513

Brochner-Mortensen, J.; Haahr, J. \& Christoffersen, J. (1974). A simple method for accurate assessment of the glomerular filtration rate in children. Scandinavian Journal of Clinical \& Laboratory Investigation, Vol.33, No.2, (April 1974) pp.140-143, ISSN 00365513

Brochner-Mortensen, J. \& Jodal, L. (2009). Reassessment of a classical single injection 51CrEDTA clearance method for determination of renal function in children and adults. Part II: Empirically determined relationships between total and one-pool clearance. Scandinavian Journal of Clinical \& Laboratory Investigation, Vol.69, No.3, pp.314-322, ISSN 0036-5513

Delanaye, P.; Mariat, C.; Cavalier, E. \& Krzesinski, J.M. (2009a). Errors induced by indexing glomerular filtration rate for body surface area: reductio ad absurdum. Nephrology Dialysis Transplantation, Vol.24, No.12, (December 2009) pp.3593-3596, ISSN 09310509

Delanaye, P.; Mariat, C.; Cavalier, E. \& Krzesinski, J.M. (2009b). Indexing glomerular filtration rate for body surface area: myth and reality. Néphrologie E Thérapeutique, Vol.5, No.7, (December 2009) pp.614-622, ISSN 1769-7255

Delanaye, P.; Radermecker, R.P.; Rorive, M.; Depas, G. \& Krzesinski, J.M. (2005). Indexing glomerular filtration rate for body surface area in obese patients is misleading: concept and example. Nephrology Dialysis Transplantation, Vol.20, No.10, (October 2005) pp.2024-2028, ISSN 0931-0509

Derek, K.S. Ng; Schwartz, G.J.; Jacobson, L.P.; Palella, F.J.; Margolick, J.B.; Warady, B.A.; Furth, S.L. \& Munoz, A. (2011). Universal GFR determination based on two time points during plasma iohexol disappearance. Kidney International, (Online June 2011), ISSN 0085-2538

DuBois, D. \& DuBois, E.F. (1915). The measurement of the surface area of man. Archives of Internal Medicine, Vol.16, pp.868-881

DuBois, D. \& DuBois, E.F. (1916). A formula to estimate the approximate surface area if height and weight be known. Archives of Internal Medicine, Vol.17, pp.863-871

Faber, H.K. \& Melcher, M.S. (1921). A modification of the Du Bois height-weight formula for surface area of newborn infants. Proceedings of the Society for Experimental Biology and Medicine, Vol.19, pp.53

Fleming, J. S. (2007). An improved equation for correcting slope-intercept measurements of glomerular filtration rate for the single exponential approximation. Nuclear Medicine Communications, Vol.28, No.4, (April 2007) pp.315-320, ISSN 0143-3636

Fleming, J.S.; Zivanovic, M.A.; Blake, G.M.; Burniston, M. \& Cosgriff, P.S. (2004). Guidelines for the measurement of glomerular filtration rate using plasma sampling. Nuclear Medicine Communications, Vol.25, No.8, (August 2004) pp.759-769, ISSN 0143-3636

Friis-Hansen, B. (1961). Body water compartments in children: changes during growth and related changes in body composition. Pediatrics, Vol.28, (August 1961) pp.169-181, ISSN 0031-4005 
Fujimoto, S.; Watanabe, T.; Sakamoto, A.; Yukawa, K. \& Morimoto, K. (1968). Studies on the physical surface area of Japanese. 18. Calculation formulas in three stages over all ages. Japanese Journal of Hygiene, Vol.23, No.5, (December 1968) pp.443-450, ISSN 0021-5082

Geddes, C.C.; Woo, Y.M. \& Brady, S. (2008). Glomerular filtration rate--what is the rationale and justification of normalizing GFR for body surface area? Nephrology Dialysis Transplantation, Vol.23, No.1, (January 2008) pp.4-6, ISSN 0931-0509

Gehan, E.A. \& George, S.L. (1970). Estimation of human body surface area from height and weight. Cancer Chemotherapy Reports, Vol.54, No.4, (August 1970) pp.225-235, ISSN 0069-0112

Hallynck, T.H.; Soep, H.H.; Thomis, J.A.; Boelaert, J.; Daneels, R. \& Dettli, L. (1981). Should clearance be normalised to body surface or to lean body mass? British Journal of Clinical Pharmacology, Vol.11, No.5, (May 1981) pp.523-526, ISSN 0306-5251

Haycock, G.B.; Schwartz, G.J. \& Wisotsky, D.H. (1978). Geometric method for measuring body surface area: a height-weight formula validated in infants, children, and adults. The Journal of Pediatrics, Vol.93, No.1, (July 1978) pp.62-66, ISSN 0022-3476

Heaf, J.G. (2007). The origin of the $1 \times 73-\mathrm{m} 2$ body surface area normalization: problems and implications. Clinical Physiology and Functional Imaging, Vol.27, No.3, (May 2007) pp.135-137, ISSN 1475-0961

Jodal, L. \& Brochner-Mortensen, J. (2009). Reassessment of a classical single injection 51CrEDTA clearance method for determination of renal function in children and adults. Part I: Analytically correct relationship between total and one-pool clearance. Scandinavian Journal of Clinical \& Laboratory Investigation, Vol.69, No.3, (May 2009) pp.305-313, ISSN 0036-5513

Kronmal, R.A. (1993). Spurious Correlation and the Fallacy of the Ratio Standard Revisited. Journal of the Royal Statistical Society Series a-Statistics in Society, Vol.156, pp.379-392, ISSN 0035-9238

Kurtin, P.S. (1988). Standardization of renal function measurements in children: kidney size versus metabolic rate. Child Nephrology and Urology, Vol.9, No.6, pp.337-339, ISSN 1012-6694

Livingston, E.H. \& Lee, S. (2001). Body surface area prediction in normal-weight and obese patients. American Journal of Physiology- Endocrinology and Metabolism, Vol.281, No.3, (September 2001) pp.586-591, ISSN 0193-1849

MacKay, E.M. (1932). Kidney weight, body size and renal function. Archives of Internal Medicine, Vol.50, pp.590-594

McCance, R.A. \& Widdowson, E.M. (1952). The correct physiological basis on which to compare infant and adult renal function. Lancet, Vol.2, No.6740, (November 1952) pp.860-862, ISSN 0140-6736

McIntosh, J.F.; Möller, R. \& Van Slycke, D.D. (1928). Studies on urea excretions. III. The influence of body size on urea output. The Journal of Clinical Investigation Vol.6, (August 1928) pp.467-483

Meeh, K. (1879). Oberflächenmessungen des menschlichen Körpers. Zeitschrift für Biologie, Vol.15, pp.425-485

Mitch, W.E. \& Walser, M. (2000). Nutritional therapy in renal disease. In: The kidney (6th edition), Brenner B.M., pp.2298-2340, WB Saunders, Philadelphia 
Mosteller, R.D. (1987). Simplified calculation of body-surface area. The New England Journal of Medicine, Vol.317, No.17, (October 1987) pp.1098, ISSN 0028-4793

Newman, E.V.; Bordley, J. \& Winternitz, J. (1944). The interrelationships of glomerular filtration rate (mannitol clearance), extracellular fluid volume, surface area of the body, and plasma concentration of mannitol. Bulletin of the Johns Hopkins Hospital Vol.75, pp.253-268

Nwoye, L.O. (1989). Body surface area of Africans: a study based on direct measurements of Nigerian males. Human Biology, Vol.61, No.3, (June 1989) pp.439-457, ISSN 00187143

Nwoye, L.O. \& Al-Shehri, M.A. (2003). A formula for the estimation of the body surface area of Saudi male adults. Saudi Medical Journal, Vol.24, No.12, (December 2003) pp.13411346, ISSN 0379-5284

Peters, A.M. (1992). Expressing glomerular filtration rate in terms of extracellular fluid volume. Nephrology Dialysis Transplantation, Vol.7, No.3, pp.205-210, ISSN 0931-0509

Peters, A.M. (2004). The kinetic basis of glomerular filtration rate measurement and new concepts of indexation to body size. European Journal of Nuclear Medicine and Molecular Imaging, Vol.31, No.1, (January 2004) pp.137-149, ISSN 1619-7070

Peters, A.M.; Allison, H. \& Ussov, WYu. (1994a). Measurement of the ratio of glomerular filtration rate to plasma volume from the technetium-99m diethylene triamine pentaacetic acid renogram: comparison with glomerular filtration rate in relation to extracellular fluid volume. European Journal of Nuclear Medicine, Vol.21, No.4, (April 1994) pp.322-327, ISSN 0340-6997

Peters, A.M.; Gordon, I. \& Sixt, R. (1994b). Normalization of glomerular filtration rate in children: body surface area, body weight or extracellular fluid volume? Journal of Nuclear Medicine, Vol.35, No.3, (March 1994) pp.438-444, ISSN 0161-5505

Peters, A.M.; Henderson, B.L. \& Lui, D. (2000). Indexed glomerular filtration rate as a function of age and body size. Clinical Science, Vol.98, No.4, (April 2000) pp.439-444, ISSN 0143-5221

Piepsz, A.; Tondeur, M. \& Ham, H. (2008). Escaping the correction for body surface area when calculating glomerular filtration rate in children. European Journal of Nuclear Medicine and Molecular Imaging, Vol.35, No.9, (September 2008) pp.1669-1672, ISSN 1619-7070

Piepsz, A.; Tondeur, M. \& Ham, H. (2009). Escaping the correction for body surface area when calculating glomerular filtration rate in children. European Journal of Nuclear Medicine and Molecular Imaging, Vol.36, No.2, (February 2009) pp.332-333, ISSN 1619-7070

Pottel, H.; Mottaghy, F.M.; Zaman, Z. \& Martens, F. (2010). On the relationship between glomerular filtration rate and serum creatinine in children. Pediatric Nephrology, Vol.25, No.5, (May 2010) pp.927-934, ISSN 0931-041X

Rubner, M. (1883). Ueber den einfluss der korpergrosse auf stoff-und draftwechsel. Zeitschrift für Biology, Vol.19, pp.535-562

Schmieder, R.E.; Beil, A.H.; Weihprecht, H. \& Messerli, F.H. (1995). How should renal hemodynamic data be indexed in obesity? Journal of the American Society of Nephrology, Vol.5, No.9, (March 1995) pp.1709-1713, ISSN 1046-6673

Schwartz, G.J.; Abraham, A. G.; Furth, S.L.; Warady, B.A. \& Munoz, A. (2010). Optimizing iohexol plasma disappearance curves to measure the glomerular filtration rate in 
children with chronic kidney disease. Kidney International, Vol.77, No.1, (January 2010) pp.65-71, ISSN 0085-2538

Shuter, B. \& Aslani, A. (2000). Body surface area: Du Bois and Du Bois revisited. European Journal of Applied Pysiology, Vol.82, No.3, (June 2000) pp.250-254, ISSN 1439-6319

Stevenson, P.H. (1937). Height-weight-surface formula for the estimation of body surface area in Chinese subjects. The Chinese Journal of Physiology, Vol.12, pp.327-334

Tanner, J.M. (1949). Fallacy of per-weight and per-surface area standards, and their relation to spurious correlation. Journal of Applied Physiology, Vol.2, No.1, (July 1949) pp.115, ISSN 0021-8987

Taylor, F.B.; Drury, D.R. \& Addis, T. (1923). The regulation of renal activity. VIII. The relation between the rate of urea secretion and the size of the kidneys. American Journal of Physiology, Vol.65, pp.55-61

Tikuisis, P.; Meunier, P. \& Jubenville, C.E. (2001). Human body surface area: measurement and prediction using three dimensional body scans. European Journal of Applied Physiology, Vol.85, No.3-4, (August 2001) pp.264-271, ISSN 1439-6319

Turner, S.T. \& Reilly, S.L. (1995). Fallacy of indexing renal and systemic hemodynamic measurements for body surface area. American Journal of Physiology, Vol.268, No.4 Pt 2, (April 1995) pp.R978-88, ISSN 0002-9513

van der Sijs, H. \& Guchelaar, H.J. (2002). Formulas for calculating body surface area. The Annals of Pharmacotherapy, Vol.36, No.2, (February 2002) pp.345-346, ISSN 1060-0280

Verbraecken, J.; Van de Heyning, P.; De Backer, W. \& Van Gaal, L. (2006). Body surface area in normal-weight, overweight, and obese adults. A comparison study. Metabolism, Vol.55, No.4, (April 2006) pp.515-524, ISSN 0026-0495

Walser, M. (1990). Progression of chronic renal failure in man. Kidney International, Vol.37, No.5, (May 1990) pp.1195-1210, ISSN 0085-2538

White, A.J. \& Strydom, W.J. (1991). Normalisation of glomerular filtration rate measurements. European Journal of Nuclear Medicine, Vol.18, No.6, pp.385-390, ISSN 0340-6997

Yu, C.Y.; Lin, C.H. \& Yang, Y.H. (2010). Human body surface area database and estimation formula. Journal of the International Society for Burn Injuries, Vol.36, No.5, (August 2010) pp.616-629, ISSN 0305-4179 


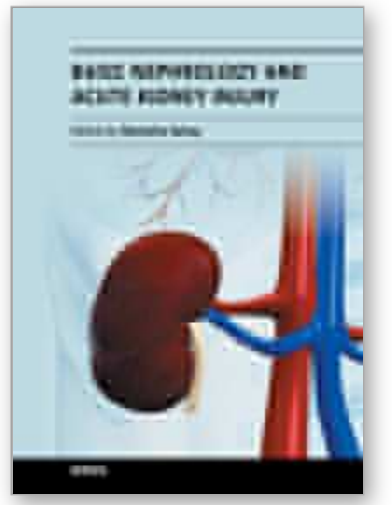

\author{
Basic Nephrology and Acute Kidney Injury \\ Edited by Prof. Manisha Sahay
}

ISBN 978-953-51-0139-0

Hard cover, 226 pages

Publisher InTech

Published online 02, March, 2012

Published in print edition March, 2012

The first section of the book covers the basics of nephrology and second section focuses on acute kidney injury. This easy to reference text examines the physiological and biochemical aspects of renal diseases - all in one convenient resource. Experts in the field discuss topics of increasing concern in nephrology including newer methods of assessing renal function. The field of acute kidney injury in nephrology is a rapidly evolving one with research translating into clinical guidelines and standards. This text brings together experts to provide an authoritative reference for management of AKI in various clinical settings. Pregnancy related AKI is an important entity which has also been discussed in detail. The recent advances in the field of critical care AKI have been incorporated as well and help the reader to update their knowledge.

\title{
How to reference
}

In order to correctly reference this scholarly work, feel free to copy and paste the following:

Liesbeth Hoste and Hans Pottel (2012). Is Body Surface Area the Appropriate Index for Glomerular Filtration Rate?, Basic Nephrology and Acute Kidney Injury, Prof. Manisha Sahay (Ed.), ISBN: 978-953-51-0139-0, InTech, Available from: http://www.intechopen.com/books/basic-nephrology-and-acute-kidney-injury/is-bodysurface-area-the-appropriate-index-for-glomerular-filtration-rate-

\section{INTECH}

open science | open minds

\section{InTech Europe}

University Campus STeP Ri

Slavka Krautzeka 83/A

51000 Rijeka, Croatia

Phone: +385 (51) 770447

Fax: +385 (51) 686166

www.intechopen.com

\section{InTech China}

Unit 405, Office Block, Hotel Equatorial Shanghai

No.65, Yan An Road (West), Shanghai, 200040, China

中国上海市延安西路65号上海国际贵都大饭店办公楼405单元

Phone: +86-21-62489820

Fax: +86-21-62489821 
(C) 2012 The Author(s). Licensee IntechOpen. This is an open access article distributed under the terms of the Creative Commons Attribution 3.0 License, which permits unrestricted use, distribution, and reproduction in any medium, provided the original work is properly cited. 